\title{
Anionic Polymerization of Vinylsilanes III. Polymerization Behavior of Trimethylvinylsilane
}

\author{
Jun-ichi OKu, Takashi Hasegawa, Toshio TaKeUchi, \\ and Mikio TAKAKI \\ Department of Applied Chemistry, Nagoya Institute of Technology, \\ Gokiso-cho, Showa-ku, Nagoya 466, Japan
}

(Received May 17, 1991)

\begin{abstract}
Polymerization behavior of trimethylvinylsilane by sec-butyllithium was investigated in the presence or absence of $N, N, N^{\prime}, N^{\prime}$-tetramethylethylenediamine (TMEDA). In the absence of TMEDA, the elimination reaction of lithium hydride which was observed apparently at $40^{\circ} \mathrm{C}$ was suppressed at $-10^{\circ} \mathrm{C}$. In the presence of TMEDA, the chain transfer reaction to the monomer occurred even at $-10^{\circ} \mathrm{C}$. Initial monomer concentration was found to affect the propagation rate considerably. In the absence of TMEDA at $-10^{\circ} \mathrm{C}$, the apparent propagation rate constant was high at high initial monomer concentration. In the presence of TMEDA, the reverse relation was observed. The former was interpreted by the association state of the active centers and the latter by the combination of two types of propagation reaction. For the isomerization reaction, low monomer concentration and high temperature were advantageous. The content of isomerized units in the polymer increased with an increase in degree of polymerization.

KEY WORDS Anionic Polymerization / Isomerization Polymerization /

Trimethylvinylsilane / $N, N, N^{\prime}, N^{\prime}$-Tetramethylethylenediamine /
\end{abstract}

We have found and studied the isomerization reaction in the anionic polymerization of vinylsilanes. ${ }^{1-3}$ The isomerization in the polymerization of trimethylvinylsilane (TMVS), which takes place with high frequency by butyllithium $/ N, N, N^{\prime}, N^{\prime}$-tetramethylethylenediamine (TMEDA), was found to be brought by the abstraction of silylmethyl proton by the propagating end anion. ${ }^{1}$ In this case, though the isomerization takes place even in the absence of TMEDA, the addition of TMEDA drastically increases the frequency of the isomerization. In the polymerization of benzyldimethylvinylsilane (BDMVS), the abstraction occurs quite regularly from the benzylic methylene in the penultimate monomer unit even in the absence of TMEDA. ${ }^{2}$ On the other hand, in the polymerization of TMVS, the intramolecular proton abstraction takes place not only from penultimate units but also from end units. ${ }^{3}$
For the polymerization of TMVS, many studies have been made by Nametkin and his successors. Their first report was about findings that TMVS and some other vinylsilanes are polymerizable anionically. ${ }^{4}$ Then they investigated the initiation reaction, ${ }^{5}$ effects of the polymerization temperature on side reactions, ${ }^{6-8}$ oligomerization, ${ }^{9,10}$ thermodynamics of the polymerization, ${ }^{11}$ and many other quarters. Their studies have clarified the nature of the polymerization reaction of vinylsilanes, but were limited to that in the absence of TMEDA, and hence the isomerization reaction was not discussed. Furthermore, little has been studied on the polymerization at lower temperature than $25^{\circ} \mathrm{C}$ even in the absence of TMEDA.

While we have clarified the isomerization manner in the polymerization of TMVS in the presence of TMEDA in the preceding papers, ${ }^{1,3}$ some points are still equivocal, e.g., the 
polymerization rate of TMVS in the presence of TMEDA, the relation between content of isomerized units (CIU) in the polymer and the polymerization conditions, side reactions in the presence of TMEDA, etc. In this paper, we intend to reveal the effects of polymerization conditions on the polymer structure and on the polymerization rate of TMVS, both in the absence and presence of TMEDA.

\section{EXPERIMENTAL}

\section{Materials}

sec-Butyllithium ( $s$-BuLi) was used after filtration and solvent substitution from cyclohexane to hexane. Hexane, TMEDA, and TMVS were purified according to the conventional method for the anionic polymerization. ${ }^{3}$

\section{Polymerization of TMVS}

Polymerizations were carried out in hexane at $-10^{\circ} \mathrm{C}$ or $40^{\circ} \mathrm{C}$. Detailed polymerization procedures and the treatment of the resulting polymers were previously described, ${ }^{1}$ except that all polymers were isolated by freezedrying.

\section{Characterization of the Polymers}

Number average molecular weights $\left(\bar{M}_{n}\right)$ were determined in benzene solution at $40^{\circ} \mathrm{C}$ by vapor pressure osmometry (VPO) using a Corona 117 molecular weight apparatus. Molecular weight distributions $\left(\bar{M}_{w} / \bar{M}_{n}\right.$, MWD) were calculated from gel permeation chromatography (GPC) data obtained in tetrahydrofuran using Toyo Soda HLC802 UR with $\mathrm{G} 2000 \mathrm{H}$ and $\mathrm{G} 3000 \mathrm{H}$ columns or using Toyo Soda HLC-802A with two GMH columns. These data were calibrated with polystyrene standards. ${ }^{1} \mathrm{H}$ NMR spectra were recorded on a Varian XL-200 spectrometer at $200 \mathrm{MHz}$ in the Fourier transform mode. Chloroform- $d_{1}$ containing $3 \%$ dichloromethane as an internal reference $(5.34 \mathrm{ppm})$ was used for the solvent.

\section{Calculation of $\mathrm{CIU}$}

CIU's were calculated from the peak areas in the ${ }^{1} \mathrm{H}$ NMR spectra of the polymers in chloroform- $d_{1}$ (shown in ref 1 ) as follows.

If the isomerization reaction occurs $n$ times except for the last monomer unit during the formation of the polymer whose degree of polymerization $\left(\overrightarrow{D P}_{n}\right)$ is $m$, the polymer should have six methyl protons of the initiator fragment, $(m-n-1)$ silylmethine protons, and $(4 n+2)$ silylmethylene protons. The relationship between $m$ and $n$ for whole polymer is hence given by

$$
\{(m-n-1)+6\} /(4 n+2)=a / b
$$

where $a$ is the area of the peak around $0.9 \mathrm{ppm}$ and $b$ is that around $0.5 \mathrm{ppm}$.

Since the structure of the end unit is necessarily $-\mathrm{CH}_{2} \mathrm{CH}_{2} \mathrm{Si}\left(\mathrm{CH}_{3}\right)_{3}$ owing to the quenching with methanol, the end unit should be excluded from the calculation of CIU. Therefore CIU in percent is defined by

$$
\mathrm{CIU}=100 n /(m-1)
$$

From eq 1 and 2, one obtains

$$
\mathrm{CIU}=100\{(m+5) b-2 a\} /(4 a+b)(m-1)(3)
$$

\section{RESULTS}

The polymerizations of TMVS were carried out at $-10^{\circ} \mathrm{C}$ and $40^{\circ} \mathrm{C}$ with initial monomerto-initiator molar ratios of 50 and 200 , both in the absence and presence of TMEDA. The feed concentration of $s$-BuLi ([I]) was fixed at about $20 \mathrm{mmoll}^{-1}$. Typical polymerization results are shown in Tables I and II. On the whole, the rate of polymerization was higher at $40^{\circ} \mathrm{C}$ than that at $-10^{\circ} \mathrm{C}$ when the other conditions were the same.

Figure 1 shows the first-order plots of the polymerization at $-10^{\circ} \mathrm{C}$. When the initial concentration of TMVS $\left([\mathrm{M}]_{0}\right)$ was fixed, the propagation reaction exhibited approximately a first-order dependence on the monomer concentration $([\mathrm{M}])$. However, the apparent 
Table 1. Polymerization of trimethylvinylsilane in hexane at $-10^{\circ} \mathrm{C}$

\begin{tabular}{|c|c|c|c|c|c|c|c|c|c|}
\hline \multirow{2}{*}{$\begin{array}{c}\text { TMVS, } \\
{[\mathrm{M}]} \\
\mathrm{moll}^{-1}\end{array}$} & \multirow{2}{*}{$\begin{array}{c}\begin{array}{c}s \text {-BuLi, } \\
{[\mathrm{II}]}\end{array} \\
\mathrm{mmoll}^{-1}\end{array}$} & \multirow{2}{*}{$\frac{\text { TMEDA }}{\mathrm{mmoll}^{-1}}$} & \multirow{2}{*}{$\frac{[\mathrm{M}]}{[\mathrm{I}]}$} & \multirow{2}{*}{$\frac{\text { Time }}{h}$} & \multirow{2}{*}{$\frac{\text { Yield }}{\%}$} & \multicolumn{2}{|c|}{$\bar{M}_{n} \times 10^{-3}$} & \multirow{2}{*}{$\bar{M}_{w} / \bar{M}_{n}^{\mathrm{a}}$} & \multirow{2}{*}{$\frac{\mathrm{CIU}^{\mathrm{b}}}{\%}$} \\
\hline & & & & & & VPO & Calcd & & \\
\hline 0.966 & 20.1 & - & 48 & 6 & 6 & 0.38 & 0.29 & - & 21 \\
\hline 0.975 & 19.5 & - & 50 & 24 & 14 & 0.67 & 0.70 & - & 15 \\
\hline 1.07 & 21.2 & - & 50 & 96 & 37 & 1.80 & 1.90 & 1.09 & 9 \\
\hline 1.07 & 21.2 & - & 50 & 168 & 56 & 2.6 & 2.8 & 1.08 & 9 \\
\hline 4.01 & 20.0 & - & 200 & 48 & 35 & 7.9 & 7.1 & 1.07 & 7 \\
\hline 3.96 & 19.9 & - & 199 & 240 & 94 & 16.8 & 18.8 & 1.14 & 6 \\
\hline 1.03 & 20.6 & 21.5 & 50 & 6 & 12 & 0.55 & 0.60 & - & 38 \\
\hline 1.00 & 18.6 & 18.9 & 54 & 24 & 22 & 1.17 & 1.19 & - & 48 \\
\hline 1.06 & 20.5 & 20.4 & 52 & 96 & 60 & 2.8 & 3.0 & 1.12 & 57 \\
\hline 1.06 & 20.5 & 20.4 & 52 & 168 & 77 & 3.4 & 3.9 & 1.13 & 62 \\
\hline 4.00 & 20.0 & 19.9 & 200 & 48 & 24 & 4.9 & 4.8 & 1.20 & 37 \\
\hline 3.96 & 19.9 & 20.0 & 199 & 240 & 71 & 9.8 & 14.2 & 1.56 & 42 \\
\hline
\end{tabular}

a Determined by GPC. b Determined by ${ }^{1} \mathrm{H}$ NMR.

Table II. Polymerization of trimethylvinylsilane in hexane at $40^{\circ} \mathrm{C}$

\begin{tabular}{|c|c|c|c|c|c|c|c|c|c|}
\hline \multirow{2}{*}{$\begin{array}{c}\text { TMVS, } \\
{[\mathrm{M}]} \\
\mathrm{moll}^{-1}\end{array}$} & \multirow{2}{*}{$\frac{\begin{array}{c}s-\mathrm{BuLi}, \\
{[\mathrm{I}]}\end{array}}{\mathrm{mmoll}^{-1}}$} & \multirow{2}{*}{$\frac{\text { TMEDA }}{\mathrm{mmoll}^{-1}}$} & \multirow{2}{*}{$\frac{[\mathrm{M}]}{[\mathrm{I}]}$} & \multirow{2}{*}{$\frac{\text { Time }}{h}$} & \multirow{2}{*}{$\frac{\text { Yield }}{\%}$} & \multicolumn{2}{|c|}{$\bar{M}_{n} \times 10^{-3}$} & \multirow{2}{*}{$\bar{M}_{w} / \bar{M}_{n}^{\mathrm{a}}$} & \multirow{2}{*}{$\frac{\mathrm{CIU}^{\mathrm{b}}}{\%}$} \\
\hline & & & & & & VPO & Calcd & & \\
\hline 1.02 & 20.2 & - & 50 & 1 & 45 & 2.1 & 2.3 & 1.17 & 7 \\
\hline 1.02 & 20.2 & - & 50 & 3 & 83 & 3.8 & 4.2 & 1.53 & 7 \\
\hline 1.02 & 20.2 & - & 50 & 6 & 69 & 3.5 & 3.5 & 1.51 & 7 \\
\hline 4.01 & 20.8 & - & 193 & 3 & 48 & 12.4 & 9.3 & 1.49 & 6 \\
\hline 4.01 & 20.8 & - & 193 & 9 & 58 & 13.2 & 11.2 & 1.49 & 6 \\
\hline 3.95 & 20.2 & - & 196 & 24 & 78 & 15.9 & 15.3 & 1.42 & 6 \\
\hline 0.980 & 19.6 & 20.5 & 50 & 1 & 44 & 1.7 & 2.2 & 1.25 & 63 \\
\hline 0.980 & 19.6 & 20.5 & 50 & 3 & 98 & 3.3 & 4.9 & 1.26 & 74 \\
\hline 0.980 & 19.6 & 20.5 & 50 & 6 & 100 & 3.3 & 5.0 & 1.54 & 71 \\
\hline 4.00 & 19.6 & 27.3 & 202 & 3 & 43 & 6.3 & 8.7 & 1.53 & 69 \\
\hline 4.00 & 19.8 & 27.3 & 202 & 9 & 81 & 7.4 & 16.4 & 1.69 & 73 \\
\hline 4.00 & 20.7 & 20.8 & 193 & 24 & 96 & 8.1 & 18.6 & 1.87 & 75 \\
\hline
\end{tabular}

a Determined by GPC. ${ }^{b}$ Determined by ${ }^{1} \mathrm{H}$ NMR.

rate constant of the propagation reaction varied with $[\mathrm{M}]_{0}$. In the absence of TMEDA, it rose with an increase in $[\mathrm{M}]_{0}$. On the other hand, an increase in $[\mathrm{M}]_{0}$ lowered it in the presence of TMEDA. In the polymerization at $40^{\circ} \mathrm{C}$ in the absence of TMEDA, such an acceleration effect of $[\mathrm{M}]_{0}$ was not observed.

Figures 2 and 3 show the relationships of $\bar{M}_{n}$ and of MWD with the polymer yield in the polymerization with $[\mathrm{M}]_{0}$ of $4 \mathrm{moll}^{-1}$. The polymers obtained at $-10^{\circ} \mathrm{C}$ in the absence of TMEDA were of narrow MWD's and had $\bar{M}_{n}$ 's close to the calculated values. When the polymerization was carried out at $-10^{\circ} \mathrm{C}$ in the presence of TMEDA, $\bar{M}_{n}$ of the polymer deviated from the calculated value and MWD broadened gradually with an increase in the yield. In the polymerization at $40^{\circ} \mathrm{C}$ in the absence of TMEDA, $\bar{M}_{n}$ was close to the calculated value but MWD was rather broad 


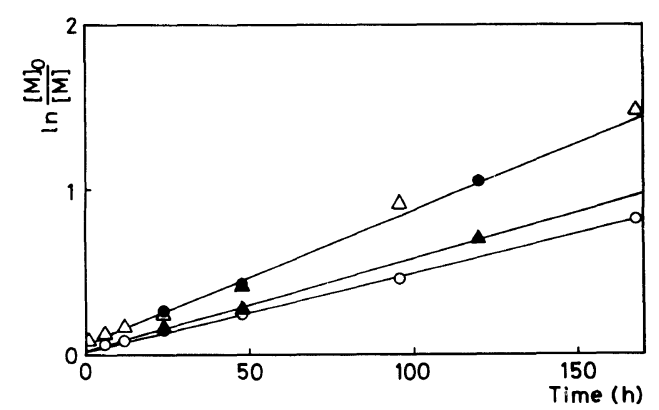

Figure 1. First-order plots for the polymerization of trimethylvinylsilane at $-10^{\circ} \mathrm{C}:[\mathrm{M}]_{0}=1 \mathrm{moll}^{-1}$, in the absence of TMEDA $(\mathrm{O}) ;[\mathrm{M}]_{0}=4 \mathrm{moll}^{-1}$, in the absence of TMEDA $(\bigcirc) ;[\mathrm{M}]_{0}=1 \mathrm{moll}^{-1}$, in the presence of TMEDA $(\triangle) ;[\mathrm{M}]_{0}=4 \mathrm{moll}^{-1}$, in the presence of TMEDA $(\mathbf{\Delta})$.

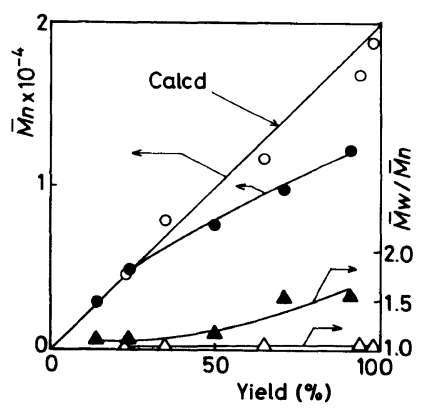

Figure 2. Relationships of $\bar{M}_{n}$ and of $\bar{M}_{w} / \bar{M}_{n}$ with the polymer yield in the polymerization of trimethylvinylsilane at $-10^{\circ} \mathrm{C}$ with the initial monomer concentration of 4 moll $1^{-1}$. In the absence of TMEDA $(O, \triangle)$ and in the presence of TMEDA

compared with that of the polymer obtained at $-10^{\circ} \mathrm{C}$. At this temperature, the polymerization in the presence of TMEDA exhibited the tendencies observed at $-10^{\circ} \mathrm{C}$ for $\bar{M}_{n}$ and MWD more remarkably.

When the polymerization was carried out in the absence of TMEDA, CIU of the polymer was less than $10 \%$ at both temperatures except for the polymers with low $\bar{M}_{n}$ 's. Figure 4 shows the relationships between $\overline{D P}_{n}$ and CIU of the polymers obtained in the presence of TMEDA. In general, CIU increases with an increase in $\overrightarrow{D P}_{n}$. Also, the lower the monomer concentration and the higher the polymerization temperature, higher CIU was provided.

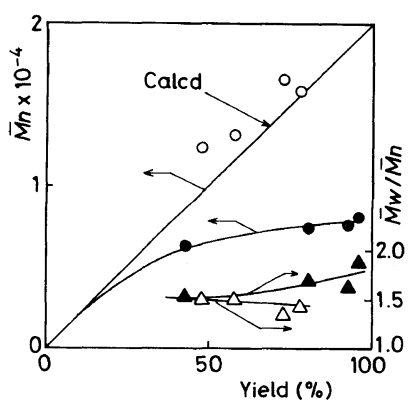

Figure 3. Relationships of $\bar{M}_{n}$ and of $\bar{M}_{w} / \bar{M}_{n}$ with the polymer yield in the polymerization of trimethylvinylsilane at $40^{\circ} \mathrm{C}$ with the initial monomer concentration of $4 \mathrm{moll}^{-1}$. In the absence of TMEDA $(O, \triangle)$ and in the presence of TMEDA

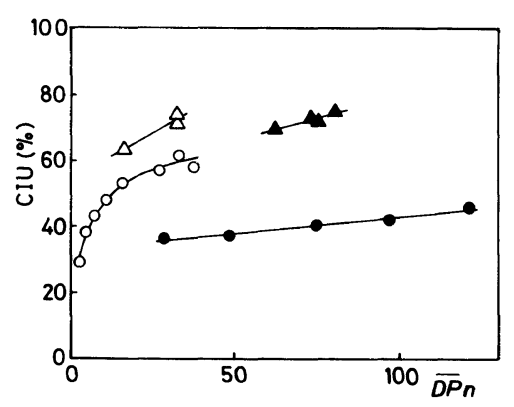

Figure 4. Relationships between degree of polymerization $\left(\overline{D P}_{n}\right)$ and content of isomerized units (CIU) in the polymerization of trimethylvinylsilane (TMVS) in the presence of TMEDA. Polymerization conditions: $[\mathrm{TMVS}]_{0}=1 \mathrm{moll}^{-1}$, at $-10^{\circ} \mathrm{C}(\mathrm{O}) ;[\mathrm{TMVS}]_{0}=1 \mathrm{~mol}$ $\mathrm{1}^{-1}$, at $40^{\circ} \mathrm{C}(\triangle) ;[\mathrm{TMVS}]_{0}=4 \mathrm{moll}^{-1}$, at $-10^{\circ} \mathrm{C}(\bigcirc)$; $[\mathrm{TMVS}]_{0}=4 \mathrm{moll}^{-1}$, at $40^{\circ} \mathrm{C}(\boldsymbol{\Delta})$.

\section{DISCUSSION}

The relation between polymerization temperature and polymer yield in the polymerization of TMVS was studied by Nametkin et $a l .^{4,6}$ in a wide range of the temeprature above $25^{\circ} \mathrm{C}$ in the absence of TMEDA. Our data, which indicate faster polymerization at higher temperature as shown in Tables I and II, are in accord with their results. The polymerization of TMVS in the presence of TMEDA was found to proceed much faster at $40^{\circ} \mathrm{C}$ than at $-10^{\circ} \mathrm{C}$ as well.

It is not very clear why the apparent prop- 
agation rate constants, which were obtained as slopes of the straight lines in Figure 1, varied with $[\mathrm{M}]_{0}$ though the propagation reaction exhibited a first-order dependence on $[\mathrm{M}]$ for a fixed $[\mathrm{M}]_{0}$ in the wide range of the polymer yield. Since the polymerization at $-10^{\circ} \mathrm{C}$ in the absence of TMEDA has rather high living nature as will be described afterward, the difference between the apparent propagation rate constants for two $[\mathrm{M}]_{0}$ values should be explained by the propagation reaction itself, not by chain transfer reactions nor termination reaction. From this viewpoint, the difference could be explained on the basis of the difference in association states of active centers. In the absence of TMEDA, the active centers are considered to be associated like other polymeric organolithium compounds in hydrocarbon solutions. ${ }^{12}$ They are also known to interact with monomers in some polymerization systems. ${ }^{13}$ In the polymerization of TMVS, trimethylsilyl groups, in not only the monomer but also the polymer, would interact with the active centers and would affect the association state of them depending on $[\mathrm{M}]_{0}$. This leads to the difference in the apparent propagation rate constants. In the case of the polymerization in the presence of TMEDA, the difference between the apparent propagation rate constants for two $[\mathrm{M}]_{0}$ values should be explained on other basis. It will be discussed hereinafter.

The polymerization behavior exhibited in Figure 2 indicates that the side reactions which take place frequently at higher temperature ${ }^{6-8}$ are considerably suppressed in the polymerization of TMVS at $-10^{\circ} \mathrm{C}$ in the absence of TMEDA. Although the chain transfer reaction to the monomer is known to occur at high temperature over $80^{\circ} \mathrm{C}$ or $100^{\circ} \mathrm{C},,^{6,7}$ the results shown in Figure 2 reveal that it occurs even at $-10^{\circ} \mathrm{C}$ in the presence of TMEDA, because $\bar{M}_{n}$ deviated unequivocally downward from the calculated value with an increase in the yield. At $40^{\circ} \mathrm{C}$, it turned out to occur more frequently in the presence of TMEDA as shown in Figure
3. Such a lowering of the temperature at which the chain transfer to the monomer takes place would be attributed to the activation of lithium hydride, which is generated through an elimination reaction, by complexation of lithium cation with TMEDA. In the polymerization at $40^{\circ} \mathrm{C}$ in the absence of TMEDA, the increase in the apparent propagation rate constant with $[\mathrm{M}]_{0}$, which was observed at $-10^{\circ} \mathrm{C}$, is not seen in Table II. This is caused by the decrease in the number of propagating species at high conversion because of more frequent elimination reaction of lithium hydride than at $-10^{\circ} \mathrm{C}$.

The isomerization reaction in the polymerization of vinylsilanes was first found by us. ${ }^{1}$ In the absence of TMEDA, CIU is not so high except for the polymers with low $\bar{M}_{n}$ 's as shown in Tables I and II. The reason why CIU is high for the low molecular weight polymer is not clear. However, an anomalous change in molecular weight with monomer conversion and frequent side reactions have been reported in the oligomerization of TMVS. ${ }^{10}$ Such a peculiarity of the oligomerization stage would affect CIU of low molecular weight polymer.

The relationships between $\overline{D P}_{n}$ and CIU in Figure 4 are well explained by the isomerization manner that we have reported is an intramolecular reaction. ${ }^{3}$ Low monomer concentration is more favorable for the isomerization reaction which is competitive with the propagation reaction. When $\overline{D P}_{n}$ has increased after some extent of monomer consumption, lowered monomer concentration becomes advantageous for the isomerization reaction. Consequently, CIU increases with $\overline{D P}_{n}$.

These relationships explain the difference between the apparent propagation rate constants for two $[\mathrm{M}]_{0}$ values in the presence of TMEDA. When the isomerization occurs in the course of the polymerization, there should be two types of propagation reaction as shown in Scheme 1. One is the propagation from a silylmethine anion. The other is that from a 


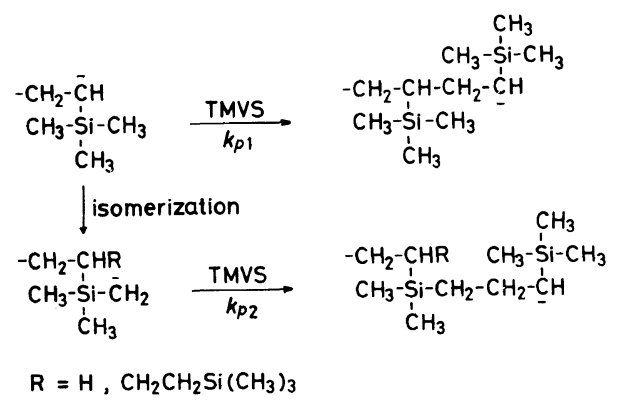

Scheme 1.

silylmethylene anion formed by the isomerization. If the rate constant of the former type of the propagation reaction $\left(k_{\mathrm{p} 1}\right)$ is smaller than that of the latter $\left(k_{\mathrm{p} 2}\right)$, the overall propagation proceeds faster when the isomerization occurs more frequently. At the lower initial monomer concentration, which results in higher CIU, the overall propagation was found to proceed faster. This indicates that the relation, $k_{\mathrm{p} 1}<k_{\mathrm{p} 2}$, holds. This relation is quite appreciable because the silylmethylene anion is less sterically hindered than the silylmethine anion.

Higher polymerization temperature was found to be favorable for the isomerization reaction. This reveals that the activation energy of the isomerization reaction is higher than that of the propagation reaction.

\section{REFERENCES}

1. R. Asami, J. Oku, M. Takeuchi, K. Nakamura, and M. Takaki, Polym. J., 20, 699 (1988).

2. J. Oku, T. Hasegawa, T. Kawakita, Y. Kondo, and M. Takaki, Macromolecules, 24, 1253 (1991).

3. J. Oku, T. Hasegawa, K. Nakamura, M. Takeuchi, M. Takaki, and R. Asami, Polym.J., 23, 195 (1991).

4. N. S. Nametkin, A. V. Topchiev, and S. G. Durgar'yan, J. Polym. Sci., C, 4, 1053 (1963).

5. N. S. Nametkin, S. G. Durgar'yan, V. I. Kopkov, V. S. Khotimskii, Dokl. Akad. Nauk. SSSR, 185, 366 (1969).

6. I. S. Bryantseva, N. M. Rukin, V. M. Vorontsov, V. S. Khotimskii, O. B. Semenov, S. G. Durgar'yan, and N. S. Nametkin, Vysokomol. Soedin., Ser. B, 20, 730 (1978).

7. I. S. Bryantseva, V. S. Khotimskii, S. G. Durgar'yan, and N. S. Nametkin, Dokl. Akad. Nauk SSSR, 251, 878 (1980).

8. I. S. Bryantseva, V. S. Khotimskii, S. G. Durgar'yan, and P. V. Petrovskii, Vysokomol. Soedin., Ser. B, 27, 149 (1985).

9. I. L. Parsamyan, I. E. Chernyakov, S. G. Durgar'yan, and N. S. Nametkin, Dokl. Akad. Nauk SSSR, 244, 116 (1979).

10. I. L. Parsamyan, O. B. Semenov, and N. S. Nametkin, Dokl. Akad. Nauk SSSR, 252, 123 (1980).

11. B. V. Lebedev, N. K. Lebedev, V. S. Khotimskii, S. G. Durgar'yan, and N. S. Nametkin, Dokl. Akad. Nauk SSSR, 259, 629 (1981).

12. R. N. Young, R. P. Quirk, and L. J. Fetters, $A d v$. Polym. Sci., 56, 7 (1984).

13. R. N. Young, R. P. Quirk, and L. J. Fetters, $A d v$. Polym. Sci., 56, 31 (1984). 